\section{THE ETHER RAUSCH}

a SAFE AND Clettin METHOD OF PRODUCING BRIEF GENERAL COMLLELE ANESTHESIA WITII ETHER

WIJLIAM 'T. COUGHLIN, M.D.

$A$ ssistnnt I'rofessor of Surgery, St. Iouls Unlversity S'r. LOUIS

I know of no perfectly satisfactory anesthetic; and that surgeons in general are not quite satisfied with our means of making surgery painless is shown by the many anesthetics, both local and general, with tlesir every methods of administration. Each method and supp anesthetic has its enthusiastic advocates, but I ideal anse that all agree with me when I say that an When in tic has yet to come into common use.

safe meth in general practice I often felt the need of : thesia therefore certain minor surgical operations. I shall, titioner, give, for the benefit of the general practration, a simple description of the technic of adminisIt may of, and my experience with, the ether Rausch. is may be that the method lere described and advocated but I I already used in certain clinics in our countrv, but I have talked with many, from all or nearly all of of principal cities, and I have met only one-Dr. Kelly Stateseland-who had seen it used in the United States. Dr. Kelly informed me that the method had has it use in this country twenty-five years ago. Why it fallen into disuse?

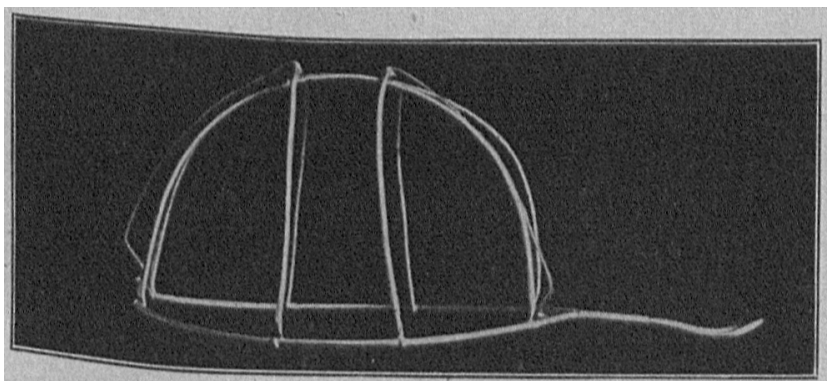

Flg. 1.-Wire frame of mask large enough to fit the face.

It is true that in some text-books on surgery attention is briefly called to the fact that a stage of primary anesthesia occurs early during the administration of arrl) that and ether. Da Costa says (quoting Parkthesia so indur is the case but that the primary an. sthesia induced lasts only half a minute. The anesand induced by the ether Rausch is profound, general usually plete and it lasts at least three minutes and other more than five. 'There is no nausen. vomiting or the mask mant effect. As the patient begins to recover it though may be reapplied and the anesthesia renewed,

Beinh this is rarely necessary.

one morning in Dresden, I visited the clinic of Lindner discinssiong, and the subject of anesthetics came under anestliosin. I was an enthusiast for local and regiona! lietlouds of for I had watched with great interest the alyone of Professor Reclus in Paris. I never sA $y$ ani? local ano knew so much about anesthesia in generial

I was anesthesia in particular as Professor Reclus.

used was asked by Professor Lindner whether I had nver even he Aether Rausch. I confessed that I had never pened to be it. Te asked the assistant if there hapIsed to be a case that morning on which it might be cal abscess lise latter replied that there was a large cervihis meths. Iindner therefore proceeded to illustrate method-a method which he had then used, he believed, more than 5,000 times. The patient was placed on the table as for an ordinary anesthetic. All instruments, drains and dressings, ctc., likely to be used were ready and close at hand. All those present were requested to be silent. The anesthetist took the mask -a large wire affair, such a one as that shown in the illustrations-and showed it to the patient, told the latter what was to be done, and admonished him to have no anxiety or alarm, explaining that the only unpleasant feature was the smell of the ether. The patient was asked to raise his arm and to keep it raised as long as he could. Meanwhile the pad at the bottom of the mask was saturated with ether, the mask was placed in position and the patient was told to breathe deeply. At about the twelfth inhalation, the arm wavered and began to fall; the mask was removed and at once the operation was begun and quickly finished. In a very short space of time three drains had been inserted and fixed in position. I was spell-bound. The mask had been removed at the first incision and the patient, though somewhat cyanosed, remained quiet. The cyanosis speedily disappeared; the patient opened his eyes, looked foolish, laughed, and asked where he was. 'T'wenty minutes or so afterward we saw him as we passed through the ward; he was eating his dinner and seemed none the worse for his operation. He assured me that he had felt no pain whatever.

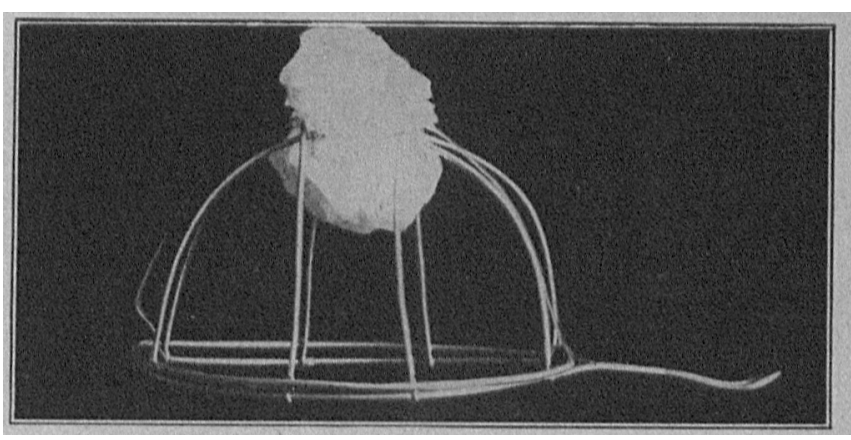

lig. 2.--The same, with pad of gauze in posttion.

The inethod of Lindner is that until recently used by me at the Washington University Hospital and now used by me at the College Clinic, St. Louis University Medical School.

Every surgeon engaged in clinical or consultant practice sees almost daily cases in which the timely and thorough performance of some minor surgical operation would in all probability have effected a speedy cure. THe sees many in which attempt at operation has been made, but without the success which the patient and perhaps the doctor expected.

I belicve that in nearly all these cases the pliysician first in attendance knows what he wants to do. He realizes. for example, that a free early incision with efficient drainage is urgently indicated in a palmar phlegmon, but he does not like to subject his patient to the risk of a general anesthetic or one which necessitates the expense of an assistant, and his patient is not willing to have any extra expense. $\mathrm{Hc}$ uses a local anesthetic, perhaps novocain, cocain or ethyl chlorid. Now you who have used these know that when tissues are acutely inflamed one is likely to cause a good deal of pain when applying the local anesthetic; and, furthermore, after having applied the local anesthetic one is usually far from having secured a complete anesthesia. The surgeon uses a local anesthetic and inflicts pain 
when operating. The patient struggles or cries or orders him to desist. At any rate, the surgeon ceases before the operation is as well done as he could wish-before it is properly done. The ease drags on with him. The process is perhaps repeated several times. The patient at last seeks relief elsewhere and the reputation of the first in attendance suffers in consequence.

It is in these cases that I advocate the use of the ether Rausch. I have used it now in more than two hundred cases, in the clinic, in the office and in the home. I have used it in cases in which I have had plenty of assistants and also in a few cases in which I have had to act both as anesthetist and as operator. I have never failed to sccure complete anesthesia, except in cases in which the patient refused to proceed beyond the first two or three inhalations.

The Rausch may be given in a variety of ways; no special appliance is necessary. The principle to remember is this: that the ether is to be administered with very little air; the air must be excluded as much as possible. I have used it in the home by means of a couple of wet towels rolled in the form of a hollow cylinder or cone with an ether-saturated towel or cottonwool over the upper end. Often I have used an ordinary derby hat. This is made to fit the patient's face closely by means of wet towels placed around the edge,

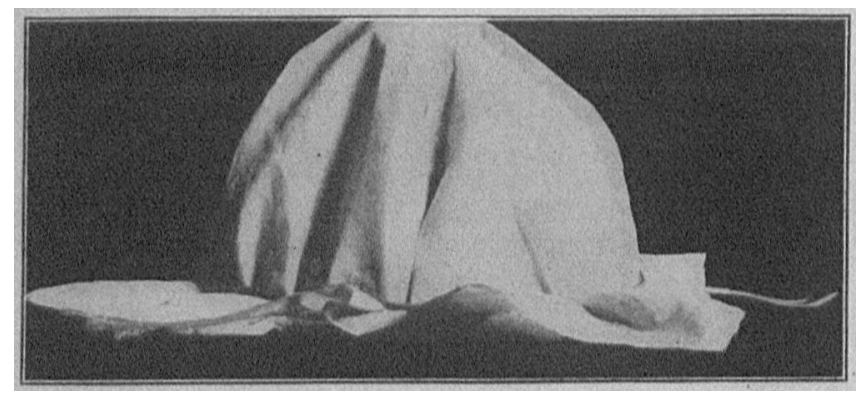

Flg. 3.-The same, now covered with olled silk.

and wet towels are placed around the sides and over a portion of the top; the wet towels exclude the air better.

I have tried the ordinary open mask in many cases. My objection to it is that I have never found it satisfactory. That it takes more time may seem a trifling objection; but the patient often becomes much frightened and refuses to proceed. The parents or relatives fear that the pationt is to be completely anesthetized and become alarmed. The patient often becomes sick at his stomach, something $I$ have never seen happen either during or after the Rausch. Furthermore, with the open mask it is difficult to tell just when primary anesthesia has bcen induced because the arm sign fails, the arm falling through fatigue.

I have been using the Rausch now for over two years; I have used it more than two hundred times. I recommend its use in all minor surgical operations which can be better done if the patient feels no pain. I have used it in opening abscesses, setting fractures, reducing dislocations, removing ingrown toe-nails, etc., etc.

I would not use it in the presence of chronic bronchitis, emphysema, marked arteriosclerosis or generally in disease of the pulmonary or cardiovascular system. Nor would I use it in any case in which the operation required more than five minutes' time to perform, or in those in which general relnxation is necessary. Neither would I use it in those pale. flabby children in whom one fears to encounter the "status lymphaticus."

Metropolitan Building.

\section{A NEW SPLINT FOR TRACTION AND COUNTER-TRACTION IN FRAC- TURES OF THE HUMERUS *}

\author{
AUGUSTIN A. CRANE, M.D.
}

Attending Surgeon, Waterbury and St. Mary's Hospitals WATERHUR, CONN.

Traction and counter-traction in the treatment of the femur as devised by Buck fifty years ago was so simple, effective and satisfactory, that no substantial improvement thereon has been made, or is needed.

Traction and counter-traction in the treatment of fractures of the humerus, while not so universally necessary, is often desirable, and sometimes essential. Its need is expressed by Scudder, Eisendrath, and other American writers, without offering practical means for meeting it. Bardenheuer, of Cologne, has exploited and developed the application of traction and counter-traction to every part of the body, giving most elaboratc details for its execution. His apparatus for the arm, however, is very complicated and unwieldy. Modifications of it have been offered by various German surgeons. the most ingenious and available being that of Hoffmann, who adapts the Mitteldorpf triangle into a rhom-

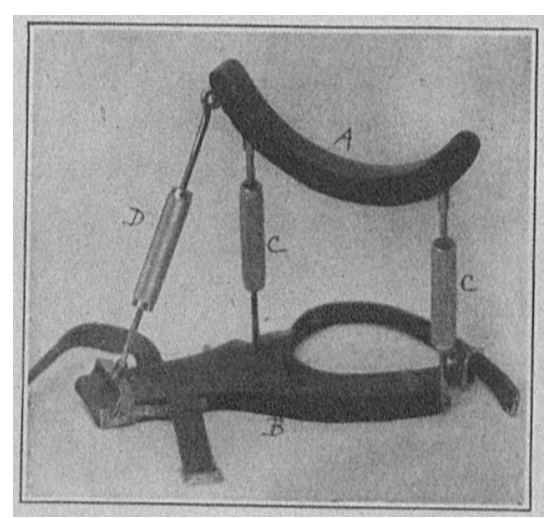

Fig. 1.-Traction splint for humerus. A, nxillary crutch : $B$. forenim bonid; $C$, pnrallel rods through which traction is sicured; $b$, guy-rod for maintaining forearm at right angle.

bus. The only ingenious and practical device I have scen described in this country, is by Osgood and Penhallow. ${ }^{1}$

They submit a tin gutter-splint, moulded to fit the arm, forearm and thorax. It would seem to be jdeal, except for not permitting of elevation, graded traction, or reversal for the opposite arm.

The distinctive features of the device which I sulmmit are an axillary crutch, $A$, for counter-traction, and a forearm board, $B$, for traction; the two being forced apart by parallel rods, $C$, extended by turnbuckles; the forearm being held meanwhile in right-angled flexion by a guy-rod, $D$, reaching to the axilla. After applying, the traction is employed and can be carried to any necessary extent. Under this powerful traction, there is opportunity for adjustment and manipulation of the fragments, and $x$-ray examination. There is ample space for coaptation splints, for applying pressure by compresses at required noints, and for frequent dressings of blisters or wounds. After full reduction and adjustment. the extreme tension can be somewhat relaxed, if the frncture js not spiral or oblique. In ordinary cases the appliance should be held to the body by a swathe; but in cases in

- Read at the semi-annual mecting of the New IInven county Medical Soclety, April 27, 1011.

1. 'I'HE: Jotixat A. il. A., July 31, 1009, p. 37. 